\title{
Escritura Ignaciana y “cosecha javeriana” del P. Mayr en la Misión de Moxos
}

\author{
Ignatian writing and “xavieran harvest” of F. Mayr \\ in Moxos mission
}

Carlos Urani Montiel ${ }^{*}$

\section{Resumen}

La etapa más fecunda de la Misión de Moxos es consecuencia directa de la llegada de misioneros extranjeros que se intensificó a partir de 1715. La producción epistolar del P. Dominik Mayr, proveniente de la Provincia de Alemania Superior y fiel seguidor de San Francisco Javier, es un ejemplo de la difusión de la correspondencia misional a través de la red de comunicación jesuita. Mi trabajo tiene como objetivo ahondar, en primer lugar, en la práctica de la escritura dentro de la misma Orden; y, en segundo, en el ministerio pastoral y la "cosecha javeriana”, como el mismo Mayr la describe, del jesuita alemán que sirvió en Moxos desde 1717 hasta su muerte en 1735. La publicación póstuma de sus cartas y el relato de viaje hacia las Indias Occidentales también lo emparentan con la figura del santo patrono de los misioneros. El éxito de la labor jesuita por las cuatro partes del mundo ad maiorem gloriam Dei, dependía en gran medida del movimiento de sus miembros y del conocimiento que implementaban en sus diferentes campos de acción.

Palabras clave: misioneros, viaje, escritura, Mayr, Moxos

\begin{abstract}
The most prolific period for Moxos' Mission is a direct consequence of the arrival of foreign missionaries that started increasing in 1715. F. Dominik Mayr's epistles, a Jesuit from the Upper Province of Germany and faithful follower of St. Francis Xavier, are an example of the spreading and distribution of missionary correspondence among the Jesuit communication network. Firstly, my work aims to analyze in depth the writing practice inside the same Order; secondly, the pastoral ministry and the "Xaverian

\footnotetext{
* Profesor titular del Departamento de Humanidades de la Universidad Autónoma de Ciudad Juárez, Chihuahua, México. Pertenece al Sistema Nacional de Investigadores del CONACyT, y es doctor en Estudios Hispánicos por parte de la Universidad de Western Ontario, en Canadá.
} 
harvest”, of Father Mayr describes it, as that of the German Jesuit who served for Moxos from 1717 until his death in 1735. The posthumous publication of his letters and the story of his journey to the West Indies also relate him with the patron saint's figure of the missionaries. The success of Jesuit's work across the four parts of the world, ad maiorem gloriam Dei, depended largely on the movement of its members and on the knowledge that they implemented on their different action fields.

Keywords: missionaries, travelling, writing, Mayr, Moxos

Recibido: 9 de julio de 2014

Evaluado: 29 de julio de 2014 
...el fin de la escritura, que es suplir la presencia, quanto a la distancia de lugares en el communicar y tratar las cosas que ocurren con los absentes; y asimismo suplir la memoria, quanto a la distancia de tiempos.

Juan de Polanco, Del officio del secretario, 1547.

Es un hecho que la gestión de los documentos escritos fue clave para el sostenimiento de las reducciones jesuitas en el Nuevo Continente. El éxito de la labor misional por las cuatro partes del mundo conocido, dependía en gran medida del traslado de sus miembros y de la reutilización del conocimiento (en ciencias y artes) implementado en sus diferentes campos de acción. El tema y objetivo de este artículo es describir el sistema de comunicación de la antigua Compañía de Jesús que operó en un momento y en varias localidades determinadas, y que realizó un despliegue de medios para mantener contacto entre sus miembros y llevar su programa ideológico a distintas partes del planeta. Esta voluntad de vínculo, de la que me ocuparé en una primera parte, obedece a una intención preestablecida por la Orden, regida por pautas estables y que incluso anteceden al mismo acto comunicativo.

Una temporalidad y espacialidad controlables son propicias para verificar la construcción de los mensajes -cifrados en forma de discursos escritos-, así como su distribución, alcance y efecto. Por lo que la producción epistolar en la Misión de Moxos en el Alto Perú de la mano del P. Dominik Mayr (1680-1735), proveniente de la Provincia jesuita de Alemania Superior, servirá, en la segunda sección del ensayo, como estudio de caso sobre la difusión y consumo de la correspondencia misional a través de la red de comunicación jesuita. Este ejemplo concreto responde a la etapa más fecunda del Moxos jesuita, consecuencia directa de la llegada de misioneros extranjeros que se intensificó a partir de $1715^{1}$. Intentaré ahondar en el ministerio pastoral y la "cosecha javeriana”, como él mismo la describe en una de sus misivas, de este jesuita alemán que misionó en el actual Bolivia a lo largo de 18 años. Tanto en su correspondencia personal (destinada a su cuñado y hermano), como profesional (al Provincial de Alemania Superior), Mayr se declara fiel seguidor de San Francisco Javier, prototipo de la figura misional de quien imitó sus pasos. La publicación póstuma de sus cartas y el relato de viaje hacia las Indias Occidentales también lo emparentan con la figura del santo patrono de los misioneros.

\section{Sistema de comunicación jesuita}

La comunicación y esfuerzos organizativos no son un fenómeno exclusivo de los jesuitas y se debe evitar el énfasis predeterminado sobre la condición única de su organización y movimiento. Lo que sí es de subrayar es la conciencia y ambición por el registro escrito como una extensión de gobierno, presentes en las instrucciones del secretario de Ignacio de Loyola, Juan de Polanco, que transmitieron (o compartieron)

\footnotetext{
${ }^{1}$ Cabe recordar que existían dos categorías de extranjeros ante las autoridades imperiales: "sospechosos" (franceses, holandeses y portugueses) y "fiables" (de Nápoles, Sicilia, Milán, Flandes, Alemania y el Franco Condado). Desde 1640 quedó vedado el paso a las Américas al primer grupo (Villalba y Vargas, 2001: 3061).
}

6 Carlos Urani Montiel. Escritura Ignaciana y “cosecha javeriana” del P. Mayr en la ... 4-24 
formas de gestión en otras órdenes o instituciones coetáneas, como el sistema de comunicación al mando de Felipe II, y que el día de hoy permiten su análisis y reconstrucción. Al respecto, Geoffrey Parker menciona tres puntos que cualquier intento comunicativo en la época debía de considerar: primero, la estructura de control y mando de cada gobierno local para formular y alcanzar sus objetivos; segundo, la red de comunicación e inteligencia creada para recopilar información venciendo posibles amenazas y obstáculos relacionados con el tiempo/distancia; y, por último, el convencimiento de que estar informado es parte de una visión estratégica dentro de un plan de gobierno ${ }^{2}$.

La descripción del sistema de comunicación jesuita contempla y estudia el conjunto de técnicas repetibles que, strictu sensu, demandaba aprendizaje, elaboración y una práctica profesional que aseguró el contacto a distancia entre sus elementos. No quedan descartados las dificultades físicas, ineficiencias operativas y fallos del sistema jesuita en la práctica. Aunque es considerable la brecha entre la comunicación real y el modelo abstracto, mi propósito es resaltar los elementos organizativos en su vertiente teórica, que es la que conservamos, sin negar la complejidad pragmática de las operaciones en las cuatro partes del mundo conocido ${ }^{3}$.

El soldado místico español nacido en el País Vasco en 1491 aprovechó los medios comunicativos en boga para mantener el control organizativo a distancia desde un punto central. Es por demás interesante reflexionar cómo fue que el retiro en Manresa y la peregrinación de Ignacio hacia Tierra Santa se transformaron en un servicio papal en Roma; es decir, que una experiencia personal devino en una empresa mundial con consecuencias políticas, económicas y culturales. La escritura alfabética fue utilizada por los jesuitas, herederos inmediatos del proyecto intelectual humanista y del método parisiense, como una herramienta para cifrar y proyectar sus experiencias adquiridas, incluso las más íntimas, en todos sus ministerios. Además, el medio impreso facilitó la comunicación entre misioneros a través de la palabra escrita a una escala hasta entonces desconocida. La imprenta contribuyó a la institucionalización de regímenes o cultos desde el ámbito de la individualidad (como los Ejercicios espirituales) y de la colectividad (breviarios, misales o catecismos) mediante la edición, traducción y difusión de varios ejemplares de una misma obra. La cantidad de impresos, "la uniformidad de su contenido y presentación formal fijarán en lo sucesivo de manera permanente y generalizada los medios de comunicación del cristiano con la divinidad”, y lo que ésta le exigía dentro de su comunidad.

La obsesión que los jesuitas compartían por la escritura se materializó en diferentes prácticas. Su impulso es subyacente a la fundación de la misma Sociedad y se amplificó con el juego de distancias y proximidades que separaban a los recursos involucrados: operarios y dependencias que fueron aumentando desde la aprobación de la Orden hasta su supresión definitiva en 1773. El sistema de comunicación de los seguidores de Ignacio en su forma escrita se divide en tres instancias discursivas: fórmulas y constituciones (normativo), cartas, crónicas o relaciones edificantes

\footnotetext{
${ }^{2}$ Parker, 1998: 12.

3 "With local newspapers rudimentary or non-existent, and inter-colonial trade still to receive the impetus that would follow the introduction of 'free trade' in the years after 1774, there was no frequent or rapid network of communication between the various viceregal and provincial capitals” (Elliott, 2006: 331).

${ }^{4}$ Ruiz, 1999: 265.
}

7 Carlos Urani Montiel. Escritura Ignaciana y “cosecha javeriana” del P. Mayr en la ... 4-24 
(narrativo) y correspondencia administrativa (de reporte), cada una con objetivos y destinatarios particulares ${ }^{5}$.

El primer género se refiere a manuales preceptivos (tratados, fórmulas, constituciones y órdenes directas contenidas en cartas institucionales) que regulaban qué clase de información era relevante para ser comunicada, así como la frecuencia, distribución y formato de su envío. La distinción entre el segundo y el tercer tipo de discurso no está dada en su presentación como tal, ya que un mismo documento puede contener las dos formas de escritura; entonces la diferencia radica en el carácter secuencial de la narración de un evento, opuesto a la descripción numerada de personas o bienes asociados a una fecha o a una localidad. La convivencia de la materia narrable con la contable en las cartas annuas (litterce annuœ) revela el valor de ambos discursos y la dependencia mutua para elaborar un reporte confiable que normalmente era leído a miles de kilómetros distancia.

Los tres tipos de discurso no ostentan jerarquía alguna; configuran el material con el que los jesuitas procuraban la fiabilidad y veracidad de sus informes, sin importar qué era exactamente lo que entendían bajo estas características. Las tensiones inherentes a los escritos normativos, narrativos y de contaduría se hallan, por un lado, en las restricciones de la exaltación moral y ejemplar de quien escribe; pero, por otro, en contenido de propaganda y de búsqueda de patrocinio, en ocasiones manipulado por una tercera mano tan evidente que el "yo narrador" se trasluce en una tercera persona, un "yo editor" con toda libertad de supresión y manipulación. Los textos narrativosdescriptivos de la Compañía estaban sujetos al trabajo de ese editor, con funciones administrativas, y al programa general de la Orden. Los secretarios de la Compañía, residentes en Roma, eran quienes editaban las cartas y lidiaban con problemas relacionados con traducción, selección, resumen (cartas abreviadas) y censura. Tales alteraciones o ajustes ponen en tela de juicio su valor como documento fidedigno $\mathrm{y}$, al mismo tiempo, abren la ventana a la libre interpretación, a lo imaginativo y ficcional de las narraciones.

Si repasamos algunos testimonios del tipo de discurso normativo se materializa la preocupación comunicativa y el afán por mantener su control. Hay que pensar que el gesto fundador promovido por Ignacio de Loyola fue un documento escrito, la Fórmula del Instituto, que dicta preceptos de la incipiente orden que los primeros jesuitas enviaron al Santo Padre en 1539. Tras su aprobación, la Fórmula fue revisada y extendida para establecer las Constituciones de la Compañía, donde se advierte que "la falta de conocimiento y de información no sea causa de algún error en deservicio de Dios nuestro Señor” ${ }^{\circ}$.

Otro buen ejemplo sobre el acopio de información es el cuestionario titulado "De algunas interrogaciones para más conocer la persona que quiere entrar en la Compañía”, contenido en el Primero examen y general, escrito alrededor de 1546 y que también forma parte de las Constituciones. En él se afirma que el aspirante a este peculiar ejército debía poseer una formación humanista (en principio independiente,

\footnotetext{
${ }^{5}$ El historiador Markus Friedrich es de los primeros en dedicar su investigación al manejo de la información administrativa jesuita a través de las cartas annuas; su trabajo contribuye a la comprensión del sistema de comunicación jesuita a nivel global, como objeto de estudio exclusivo (2008a). Sobre esta línea de trabajo hay que sumar el esfuerzo de Luke Clossey (2008), Galaxis Borja González (2012), Gilberto López Castillo (2013) y Albrecht Classen (2014).

${ }^{6}$ Constituciones, 1993: 131.
}

8 Carlos Urani Montiel. Escritura Ignaciana y “cosecha javeriana” del P. Mayr en la ... 4-24 
pero después diseñada también por los jesuitas), dominar la filosofía, ser humilde, servir a otros y abrazar el compromiso de formarse según las Constituciones y los Ejercicios espirituales para sentir y llegar a ver el dolor de Cristo y así estar en su verdadera compañía $^{7}$. El aspirante entregaba su voluntad y su intelecto al General, quien a su vez estaba a las órdenes del Papa. Las cartas y cuestionarios que determinaban la vocación, votos y funciones de los novicios hacían de los asuntos y características personales materia burocrática. Estos despachos estandarizados recibían el nombre de informatio ad gradum, ad gubernationem o ad dimittendum. La gestión de la información del candidato incluía la selección de cuatro jesuitas locales, más cuatro consultores del Provincial, quienes recopilaban la información del futuro novicio. El reporte era resumido, evaluado y compilado en dicha informatio, que al final era enviada a Roma ${ }^{8}$.

La fuente primordial para reconstruir los lazos comunicativos de la Compañía son las cartas annuas y los catálogos de personal. Gracias a los inventarios de misioneros durante su labor de evangelización en el espacio geográfico americano es que tenemos noticia del recorrido geopolítico de los integrantes de la Orden. Este tipo de correspondencia formó parte del intercambio de información y fue objeto de un control normativo y de estandarización. Bajo una posible influencia de las epístolas de San Pablo y según el modelo humanista de contabilidad y compendio, el laboratorio epistolar jesuita surgió como una manifestación original que sometía a normas colectivas las prácticas escriturales de cada uno de sus miembros. El devenir de cada casa era narrado en la lengua del país y traducido al latín; los sucesos cotidianos adquirían cualidades edificantes y se enviaban a Roma, desde donde eran editados y retransmitidos hacia toda la red. Debido al intenso tráfico epistolar la Compañía se vio inmiscuida en el trabajo de recopilación, resguardo y conservación de los documentos, lo que derivó en la existencia de inmuebles físicos de acopio, preservación y consulta, esto es, de un archivo.

En una carta de San Ignacio dirigida al P. Pedro Fabro, fechada el 10 de diciembre de 1542, yace la teoría y práctica epistolar. El fundador de la Orden anota los riesgos del acto de recepción según el tipo de lector y explica a su colega que una cosa es hablar en presencia y otra escribir en ausencia, para lo cual:

"Cada uno de la Compañía, cuando quisiese escribir por acá, escribiese una carta principal, la cual se pudiese mostrar a cualquier persona; porque a muchos que no son bien aficionados, y desean ver nuestras cartas, no las osamos mostrar por no traer ni guardar orden alguna, y hablando de cosas impertinentes en ellas; y ellos sabiendo que tenemos cartas de uno y de otro, pasamos mucha afrenta, y damos más desedificación que edificación alguna"9.

La producción epistolar se basaba en una estrategia de composición dual de las misivas para guiar la lectura de diferentes destinatarios. Las "cartas principales" servían para encender el fervor del novicio y granjear el apoyo de algún particular; mientras que las "hijuelas", que serían como anexos o apéndices, eran útiles para asuntos más delicados dirigidos solo a los religiosos de alto rango en la organización:

\footnotetext{
${ }^{7}$ Ibíd.: 63-65.

${ }^{8}$ Friedrich, 2008b: 547. Sobre este aspecto también véase el artículo de Marina Massimi, que trata sobre el ingenio y temperamento en los catálogos del personal de la Compañía de Jesús (2008).

${ }^{9}$ Ignacio, 1963: 648.
}

9 Carlos Urani Montiel. Escritura Ignaciana y “cosecha javeriana” del P. Mayr en la ... 4-24 
"En la carta principal escribiendo [sic] lo que cada uno hace en sermones, confesiones, ejercicios y en otras espirituales obras, según que Dios N.S. obrare por cada uno, como pueda ser a mayor edificación de los oidores o lectores; $y$ cuando, la tierra siendo estéril, faltase que escribir, en pocas palabras de la salud corporal, razonamiento con alguno o de otra cosa semejante, no mezclando cosas algunas impertinentes, mas dejando para las hijuelas, en las cuales pueden venir las datas de las cartas recibidas, y el gozo espiritual y sentimiento habido por ellas, todas enfermedades, nuevas, negocios, y el dilatarse en palabras exhortando" ${ }^{10}$.

En cuanto a la técnica de composición de las misivas, Ignacio sugiere la reflexión y la consecuente reescritura y subraya la constancia o fijación temporal del discurso escrito. Las siguientes líneas apuntan hacia una regularización y estructuración sistemática de los contenidos:

"La carta principal yo la escribo una vez, narrando las cosas que muestran edificación, y después, mirando y corrigiendo, haciendo cuenta que todos la han de ver, torno a escribir o hacer escribir otra vez, porque lo que se escribe es aún mucho más de mirar que lo que se habla; porque la escritura queda, y da siempre testimonio, y no se puede así bien soldar ni glosar tan fácilmente como cuando hablamos" $"$.

Sobre los lineamientos de esta carta personal, se escribió el texto prescriptivo más importante sobre el manejo de la correspondencia jesuita: la Formula scribendi, que cuenta con varias ediciones y correcciones desde su lanzamiento en 1560 hasta su impresión final, veinte años después. La esencia de esta Formula se encuentra tanto en las cartas del de Loyola como en otro tratado redactado en 1547, el Del officio del secretario que estará en Roma, que ofreció reglas adicionales para regular el tráfico de misivas. El texto, perteneciente a la pluma de Juan de Polanco, especifica el campo de acción de su empleo: "todo lo que se trata con absentes, y especialmente lo que toca al escrevir, ansi lo que de otras partes se recibe, como lo que de aquí se enbia o se guarda”. Para que el oficio beneficiara a la Compañía eran "necessarias cinco industrias generales”. Las primeras dos se encargan de recibir las letras y de saber de dónde vienen y cuándo fueron escritas. La tercera destreza se encarga del cómo de la escritura (inventio y dispositio) y la forma en que deben ser enviadas. La cuarta puntualiza "las nuevas que se sacan de cartas de otros de fuera”, y la última indica cómo guardar todo lo que importa en las otras cuatro habilidades o industrias ${ }^{12}$.

Los objetivos de la escritura ignaciana trazan un eje que conecta el mundo espiritual con el terrenal. La distinción de contenidos y el lugar específico para cada uno de ellos establecen en detalle una rúbrica para la manufactura epistolar de los suyos. Otra subdivisión consideraba el flujo de la correspondencia: de entrada, dirigida hacia el centro administrativo, y de salida, hacia el exterior para los jesuitas que trabajaban en los campos apostólicos. Este sistema también sugiere cómo la Compañía podía pasar de los géneros diseñados exclusivamente para el empleo interno a los géneros destinados a ser utilizados entre los externos. "What is more, the organizational machinery to accomplish the task of edification was strikingly parallel in structure to that employed in

\footnotetext{
${ }^{10}$ Ibíd.: 649.

${ }^{11}$ Ibíd.: 649-650.

12 Polanco, 1960: 313-325.
} 
the making and communicating of administrative decisions”"13. El paso de una escritura privada a otra abierta resulta de la conjunción de objetivos: edificar, ganar patrocinio y reclutar externos. Es de notar la distinción entre cartas de administración interna y las diseñadas para ser difundidas entre el público lector, que bien podría pertenecer, o no, a la corporación. Friedrich añade que la evolución gradual de dicha distinción entre el público en general y el destinatario jesuita da pauta para repensar la demanda y publicidad de la correspondencia jesuita ${ }^{14}$.

Uno de los títulos para nombrar la colección y reedición de las cartas annuas a principios del siglo XVIII en el contexto francés y de la Nueva Francia era el de Letras edificantes y curiosas, antologías impresas producto de la administración de recursos informativos a nivel local, que se convirtieron en fuente de los descubrimientos y diversidad del mundo cristiano (o por convertir), disponibles en breves capítulos dispuestos ante la curiosidad del lector común. Con estas ediciones, la recepción del proyecto global de misión convertía al acto particular del religioso en un evento simbólico y de entretenimiento para una gran audiencia. Así pues, el itinerario del jesuita quedaba registrado, fortaleciendo a la Orden, ganando favores y haciendo de la aventura misional un subgénero narrativo de bastante aceptación.

Los reportes misionales y las cartas annuas están pensados a priori para su consumo fuera de la Orden. Ambos registros describen los deberes del jesuita según su provincia; no contienen teología sino detalles de la vida diaria; pormenorizan los deberes y el comportamiento del misionero dentro de su residencia; dictan la relación de la Compañía con el mundo secular al que está inscrito y con el que interactúa; y se ajustan a las normas ignacianas de comunicación, es decir, son sistemáticos y edificantes. Los reportes están escritos en lengua vernácula, mientras que las cartas, como las hijuelas por ejemplo, en latín. También difieren en destinatario implícito, longitud y en que en los reportes hay espacio narrativo para hablar sobre los usos de la flora y fauna de cada localidad.

Sin embargo, la descripción de hábitos y costumbres de los nativos no fue estandarizada. La reflexión del jesuita en ultramar antecede al trabajo etnográfico, pero contiene tintes dramático-teatrales, disputas dialógicas y polémicas, ambiciones o exaltaciones individuales que aparecen bajo una retórica de santidad y utopía. Para Ines Zupanov estos tópicos coinciden con intereses y acciones profanas de la Compañía, tales como la compilación de información, estandarización del conocimiento sobre tierras lejanas, proselitismo y burocracia interna o con otras instituciones ${ }^{15}$. La habilidad o industria del jesuita consistía en acomodar su experiencia a esos tópicos y lograr que su escritura transmitiera información práctica y lista para su reutilización y adaptación a otros contextos.

Las continuas reelaboraciones sobre el cómo y cuándo habían de enviarse las cartas y reportes sugieren que los jesuitas no satisficieron de forma inmediata las demandas de la curia en Roma, lugar crucial para el sistema de correspondencia donde coincidían sucesos locales, aunque distantes, para instituir normas globales; pero que sí cultivaron la idea del funcionamiento en red que daba aviso, resguardo y contacto a una empresa de proporciones planetarias. Asimismo la maquinaria organizativa requerida

\footnotetext{
${ }^{13}$ Harris, 1996: 302.

${ }^{14}$ Friedrich, 2008a: 7.

15 Zupanov, 2001: 7.
}

11 Carlos Urani Montiel. Escritura Ignaciana y “cosecha javeriana” del P. Mayr en la ... 4-24 
para la edificación fue paralela a la estructura empleada para la toma y comunicación de decisiones administrativas. La constante circulación de textos y la obsesión por el registro, no solo encuentran una justificación en los objetivos espirituales de evangelización, sino en la creación de un catálogo de posibles situaciones y respuestas a las que el misionero se podía enfrentar. Las cartas annuas guiaban el comportamiento moral del jesuita, de tal forma que el examen de conciencia particular se insinuaba a través del reporte anual, en donde el detalle de los eventos enumera ocasiones y hace un inventario de escenarios viables -y de gran interés para el futuro misionero- con coordenadas geopolíticas y eventos históricos concretos.

\section{La “cosecha javeriana” del P. Mayr}

La actividad misional en ultramar se incorporó a una geografía simbólica en la que personajes y latitudes lejanos poblaban la lectura atenta de las crónicas jesuitas desde los colegios y noviciados de la Compañía en Europa Central. La insistente solicitud de los misioneros que intentaban cruzar el Atlántico está bien documentada. Sabemos que la competencia entre estos extranjeros por oficiar en las reducciones americanas sobrepasaba los lugares disponibles y los recursos para su traslado, ya que la manutención del jesuita aumentaba cuando se encontraba de viaje ${ }^{16}$. Por lo tanto, es rara la noticia sobre expediciones de novicios, colegiales o profesos de primeros votos, ya que la Sociedad de Jesús solo invertía en sus mejores elementos que habían solicitado el embarque en repetidas ocasiones, fueran estos sacerdotes de cuatro votos o hermanos coadjutores destacados por sus conocimientos artísticos o científicos, dispuestos a ofrecer sus servicios allende el mar. Así que el promedio de edad de los misioneros de Europa Central al momento de su embarque era de 28 a 33 años ${ }^{17}$.

El martirio en septiembre de 1702 de uno de los fundadores del proyecto misional en los Llanos de Moxos, el P. Cipriano Barace, funciona como antesala de la etapa más fecunda para estas famosas reducciones, dependientes de la Provincia Peruana. La muerte del jesuita navarro en la zona de Baures tuvo repercusiones a nivel local, pero también en el Viejo Continente. La noticia llegó pronto a Alemania gracias a la carta del P. Juan Antonio Nyel, fechada en mayo de 1705 y dirigida desde Lima al rector del Colegio de Estrasburgo, misma que fue traducida al francés y antologada en el octavo volumen de las Lettres édifiantes et curieuses $^{18}$. La proyección mediática del martirio de Barace se comprueba con la publicación en España (1711 y 1757), la traducción al francés (1713, 1732 y 1781) y al inglés (1714) de extractos de dicha carta y, sobre todo, de algunos pasajes pertenecientes a la relación oficial compuesta por el entonces superior del conjunto misional en Moxos, el P. Antonio Orellana, quien consiguió el favor real para imprimirla en Lima en 1704.

El efecto de lectura deseado por la crónica del martirio es más que evidente. En el texto base de Orellana, es decir en la Relacion summaria de la vida, y dichosa muerte del V.P. Cypriano Baraze, la “Aprobación” advierte que el lector escrupuloso hallará "fértil materia para su edificación y liciones para avivar la fe”. Más adelante un epigrama insiste en que la muerte de Barace “de mil almas será grano fecundo”. El

\footnotetext{
${ }^{16}$ Bailey, 1999: 3-16; Cushner, 2006: 13-30.

${ }^{17}$ Galán García, 1995: 197-352.

${ }^{18}$ Nyel, 1708: 9-10.
} 
"Prólogo al lector" añade que la obra intenta "imprimir en los ánimos de los que le leyeren, generosos alientos de imitarle"; y en el séptimo capítulo Orellana concluye con la esperanza de que se haya despertado "el fervor de muchos, para la imitación de tan ilustre ejemplo"19. Fue así que el actual Departamento boliviano del Beni ingresó al bagaje literario y a la cartografía simbólica del público lector (miembros o no de la Compañía, europeos o del Nuevo Mundo) del siglo XVIII. Los novicios en las diferentes provincias jesuitas leían la relación del protomártir de las misiones peruanas. La difusión del impreso y el impacto de lectura lograron la infusión de capital y de recursos humanos en una coyuntura histórica vital para el reclutamiento y envío de misioneros extranjeros a las reducciones americanas.

La expedición del Procurador Francisco de Rotalde, de Sevilla a las Indias en 1717, fue la primera que la Casa de la Contratación autorizó hacia la Misión de Moxos como destino final. Once de los diecisiete misioneros que se embarcaron en Andalucía fueron destinados a esas reducciones; siete de ellos eran extranjeros; uno de la provincia de Milán, y el resto de la de Alemania Superior. Ahí encontramos a Dominik Mayr, misionero de origen germano, seleccionado como sujeto de estudio con el objetivo de concretizar el suministro de misioneros extranjeros, su larga jornada, el ministerio en

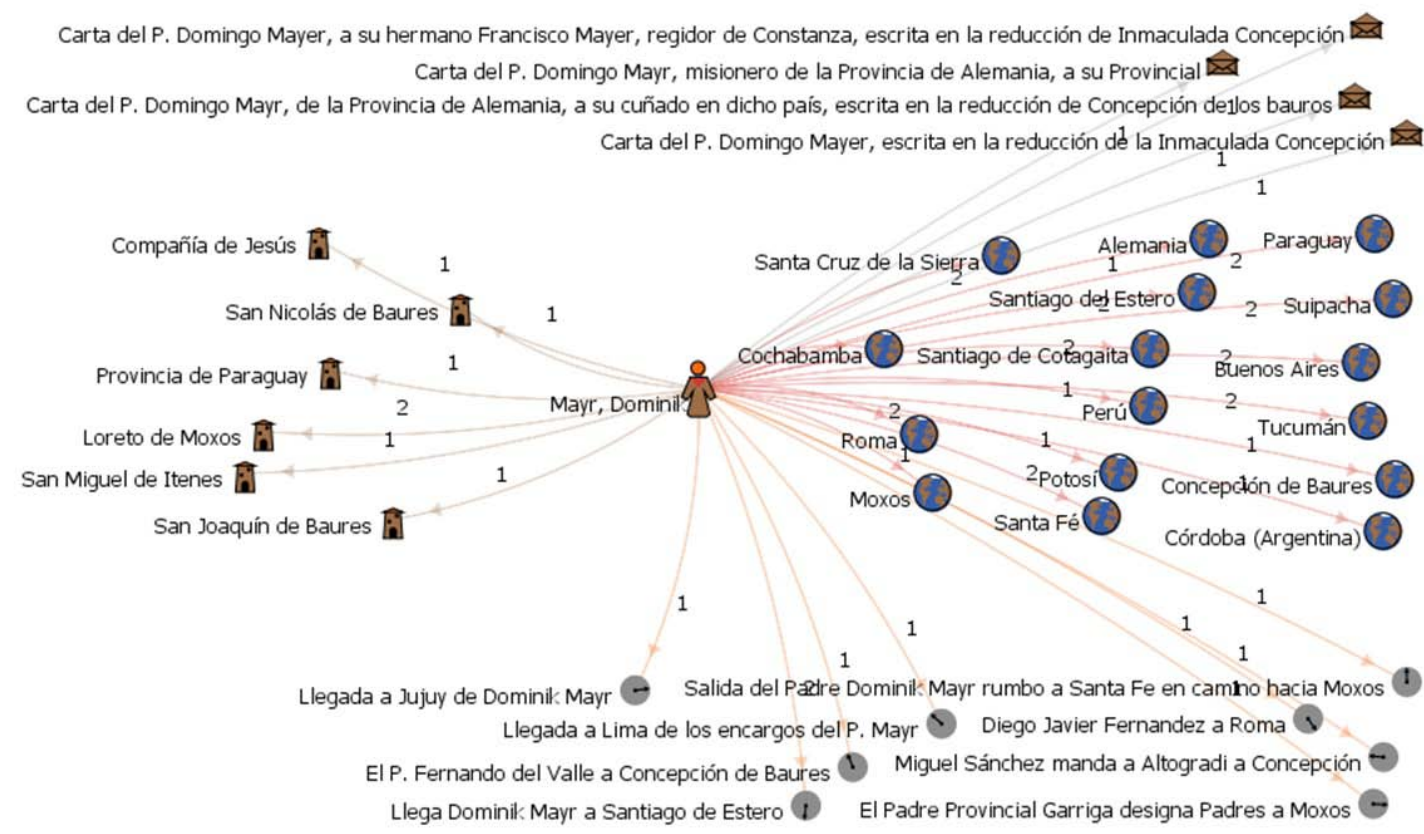

Fig. 1. Obras de Dominik Mayr

tierras americanas y, principalmente, la producción epistolar de un jesuita no hispano en las reducciones de Moxos. En la figura 1 es posible visualizar los testimonios conservados de su puño y letra ${ }^{20}$.

\footnotetext{
${ }^{19}$ Orellana, 1704: s. p.

${ }^{20}$ En el contexto novohispano, el investigador Gilberto López Castillo, entiende que el epistolario es una fuente privilegiada de información, "en virtud que ofrece un marcapasos de los avances y retrocesos de la evangelización, de la interacción entre los actores sociales de este proceso y de los cambios en los mecanismos de administración jesuítica” (2013: 121).
} 
El grafo ilustra los eventos (icono-reloj), las ciudades (icono-mundo) y las instituciones jesuitas (icono-campanario) que cubren el itinerario del sacerdote hacia y en las misiones. Las personas mencionadas en sus cuatro misivas (icono-carta) son allegados de su tierra natal, compañeros de viaje o de la Provincia de Paraguay que lo auxiliaron durante la expedición. Sin embargo, llama la atención un par de figuras que Mayr no conoció directamente, pero que fueron ejemplares ante su entusiasmo sobre la travesía trasatlántica. Me refiero a los misioneros navarros Cipriano Barace, mártir de Moxos, y a Francisco Javier, quien murió de pleuresía a finales de 1552 en los litorales del imperio chino.

Para hablar sobre la presencia de jesuitas extranjeros en la Provincia Peruana, hay que remontarse a la gestión política obtenida por la Compañía en diciembre de 1664 para el envío de misioneros no españoles a América. El punto de partida se localiza cuando la comisión jesuita en la Corte de Felipe IV levantó la prohibición del envío de extranjeros a las Indias Occidentales y la Cédula Real autorizó que una cuarta parte de las expediciones de la Sociedad de Jesús fuera de otras naciones. Uno de los argumentos de mayor peso para el traslado de refuerzos aducía la relativa escasez de personal en las provincias hispanas para las misiones de ultramar ${ }^{21}$. Con esto, nos informa el especialista en el tema, Vicente Sierra, "se inician los envíos de jesuitas alemanes, primero en pequeñas cantidades, luego en número cada vez mayor, pero siempre regulares" 22 .

A pesar del decreto de 1664, el Consejo de Indias presentó cláusulas restrictivas al sistema de reclutamiento y envío de misioneros: solo se daba licencia a los provenientes de territorios de la casa de Austria, que tuvieran permiso del General y que permanecieran un año en la Provincia de Toledo. Por lo que el P. Sebastián Izquierdo, titular en Roma de la Asistencia hispana, dirigió en 1673 un razonado "Memorial" al Procurador General de Indias en la Corte de Madrid, en donde reafirma la obligación que el monarca español tenía, so pena de cargos de conciencia, respecto a la evangelización de los naturales gentiles de sus dominios. Además, la cuestión podía ser defendida en términos estadísticos: los 9139 operarios de las nueve provincias europeas (cuatro alemanas con 6601 y cinco italianas con 2538) superaban con creces a los 2040 jesuitas de las cinco provincias españolas (Andalucía, Aragón, Castilla, Toledo y Cerdeña). El número de voluntarios aptos para el arduo trabajo misional también rebasaba la aportación hispana. El Procurador pedía paso franco y exento de limitación a los extranjeros de la Compañía.

Es de notar que el documento romano de 1673 estaba al día con los avances en el Virreinato del Perú. Sebastián Izquierdo menciona las misiones de Juli y Santa Cruz de la Sierra, “y ahora han entrado algunos Padres a convertir otros, comenzando por la nación de los Mojos, y han descubierto tantas multitudes de infieles que, para irlos convirtiendo, es necesario una grande multitud de operarios" 23 . El "Memorial" de

\footnotetext{
21 La octava Congregación General (1615-1616) “internacionalizó” las misiones, es decir, las hizo empresa común de toda la Compañía. "De esta manera llegarían a las Indias en 1617 los primeros cuatro jesuitas alemanes”; sin embargo, también hubo otra prohibición en 1654 contra el viaje de los súbditos de los Austrias en Italia, Alemania o Flandes (Villalba y Vargas, 2001: 3061).

22 Sierra, 1944: 106. Actualmente la presencia de estudiantes y voluntarios germanos en comunidades indígenas bolivianas es realmente significativa. Al respecto pueden consultarse los proyectos bilaterales e instituciones participantes en la página de la Embajada Alemana en La Paz, Bolivia: http://www.lapaz.diplo.de/.

${ }^{23}$ Izquierdo, 1944: 407.
} 
Izquierdo tuvo su efecto y por fin las autoridades dieron a conocer en marzo de 1674, la "Real Cédula de la Reina Gobernadora [Mariana de Austria] al General de la Compañía de Jesús”, que le daba aviso al P. Paolo Oliva,

"que para las misiones de las Indias pueda su religión enviar la tercia parte de religiosos extranjeros... siendo Vasallos de esta Corona y de los estados ereditarios de la casa de Austria". Las condiciones eran que "la aprobación la traygan los religiosos extrangeros que se eligieren del Prouincial de la prouincia donde estuuieren asta que bayan a embarcarse, con calidad que no se ayan de emplear en otros ussos que los que predicare el Santo Euangelio a los Indios ${ }^{24}$.

La noticia fue celebrada en las casas europeas de la Compañía y de hecho, la última restricción fue rápidamente absuelta, ya que eran los superiores de cada dependencia, y no la administración real, quienes dispusieron del destino y funciones de sus miembros.

La gran afluencia de misioneros de origen germano halló sus propios cauces ante la falta de información concreta de los funcionarios españoles sobre los límites exactos del imperio. Además, los extranjeros jesuitas, hábiles en la adquisición de lenguas, cambiaban sus nombres para ajustarse tanto a la fonética como a la extensión territorial hispana. No obstante, el bloqueo de las vías marítimas durante la Guerra de Sucesión española (1701-1714) postergó el envío de operarios al Nuevo Mundo. Los permisos otorgados durante la dinastía borbónica se renovaron e incluso se extendieron en beneficio de la Compañía, siempre influyente en la Corte española. En 1715, Felipe V concedió el pase a jesuitas de Polonia, Baviera (Alemania Superior), Bélgica y algunos estados italianos (Venecia y Génova), lo que logró “calmar las ansias de los muchos que pedían ser enviados a las misiones" 25 . La mayoría de los jesuitas de habla alemana en América ejercieron el apostolado en un espacio de frontera -lugar implícito de su escritura-, ya fuera en los márgenes exteriores al norte de la Nueva España o al sur en Río de la Plata o Chile; así como en los límites interiores del Chaco, el Altiplano andino y la Amazonía.

Este es el contexto de la labor misional del P. Dominik (Dominicus o Domingo) Mayr en Moxos, específicamente en Concepción de Baures (figura 2). Nació en agosto de 1680 en Wald, en la región de Suabia (actual estado de Baden-Württemberg), ingresó a la Orden a sus 18 años en el Noviciado de Landsberg (en Baviera) para concluir sus estudios de filosofía que había iniciado de manera secular en la Universidad de Friburgo. En 1700 terminó sus años de novicio en la misma casa de Landsberg, dependiente de la Provincia Jesuita de Alemania Superior. Durante los siguientes cinco años fue profesor de gramática en Friburgo hasta que en 1705 retomó los estudios superiores de teología, esta vez en Universidad de Ingolstadt. Para 1709 recibía las sagradas órdenes en la catedral de Eichstätt y daba cátedra de Humanidades en la Universidad de Dillingen (Dilinga) donde profesó sus cuartos votos en 1713 y residió hasta marzo de $1716^{26}$.

\footnotetext{
${ }^{24}$ Cédula editada por Pastells, 1918: 79-83.

25 Sierra, 1944: 113.

${ }^{26}$ Stadelmann, 2002: 280-283.
} 


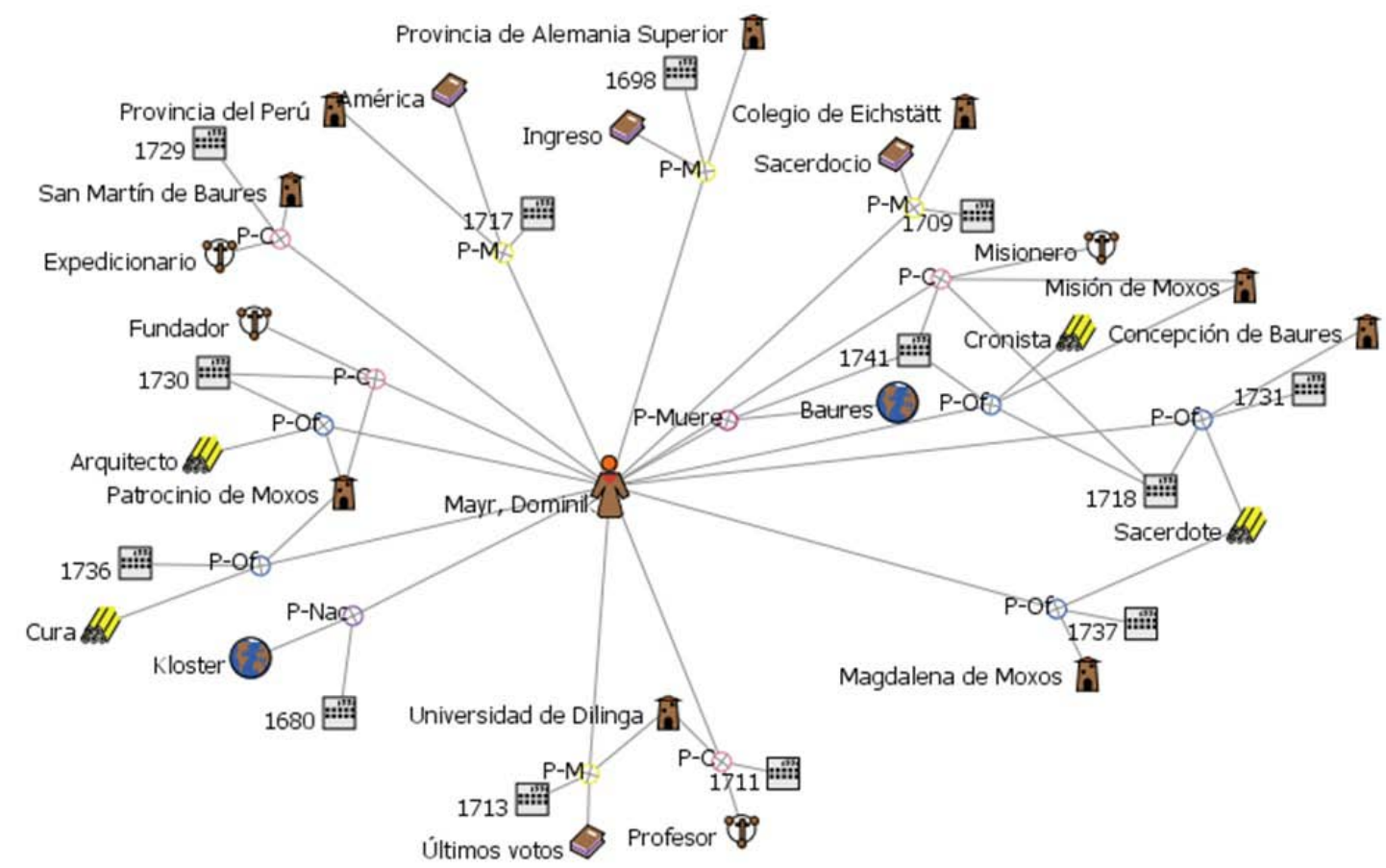

Fig. 2. Red personal de Dominik Mayr (1680-1741) ${ }^{27}$

Sobre su deseo de cruzar el Atlántico también tenemos noticia. A partir de 1710 dirigía anualmente una carta al Padre General en Roma solicitando el traslado a América. Mayr formaba parte de un grupo de sacerdotes jesuitas que perseguían el mismo fin y que se reunía en el Colegio de Constanza. A inicios de abril de 1716 Mayr y otros cinco Padres recibieron la aprobación de sus superiores y el día 24 emprendieron el viaje mediterráneo a través de Suiza con dirección a Marsella para embarcarse rumbo a Sevilla. Ya en el Hospicio de Indias la comitiva germana, de un promedio de 36 años, se entrevistó con el Procurador Francisco de Rotalde, quien había conseguido la concesión de embarque el mismo año de $1716^{28}$.

Al mes de su llegada Mayr mandó una carta personal a su cuñado en Alemania, fechada el 30 de septiembre de 1718, donde narra con detalle la ruta terrestre por Sudamérica en la que "innumerables fueron las penalidades y peligros que pasamos, pero, gracias a Dios, estamos bien de salud y animosos”. La expedición salió de Sevilla el 12 de junio de 1717, llegó a Buenos Aires el mismo año y de ahí comenzó un nuevo viaje por tierra de casi un año pasando por Santiago del Estero, Tucumán, Jujuy, Tarija, Potosí en enero de 1718, Oruro, Cochabamba y Santa Cruz de la Sierra el 9 de abril, en donde Mayr recuerda que ese día "era también justamente el segundo aniversario de mi

\footnotetext{
27 El grafo muestra el recorrido biográfico del misionero (icono-jesuita) junto con sus asociaciones a residencias dependientes de la Compañía (icono-campanario), lugares geográficos (icono-mundo), fechas (icono-calendario), módulos de formación (icono-libro), cargos ejercidos (icono-cruz) y su labor misional (icono-maderas).

${ }^{28}$ Pastells, 1946: 79-82. Los otros 5 jesuitas de la Provincia de Alemania Superior con destino a Moxos y compañeros de Mayr fueron Franz Xaver Dürrhaim (natural de Augsburgo), Pedro Pyron (de Neuhausen), Sebastián Schmid (de Altöting), José Schwentner (de Ellwangen) y Kaspar von der Weide (oriundo de Nidwalden). Este último no aparece en la patente de salida de la Casa de la Contratación (Galán García, 1995: 207), pero sí en las cartas de Mayr (1969a: 227; 1969b: 244), de Dürrhaim (1969: 194) y en la investigación de Vicente Sierra (1944: 372).
} 


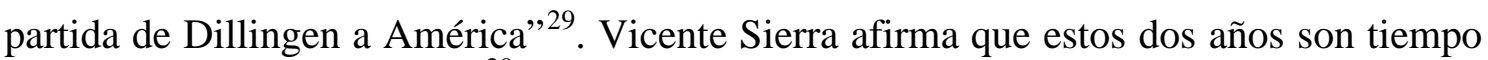
record de duración del viaje ${ }^{30}$. En la Residencia de Santa Cruz, narra el viajero, "el P. Superior nos retuvo 4 meses... No podíamos reunir antes las embarcaciones y los remeros que necesitábamos para llegar por los ríos Marmoré y Guapaix a nuestros lejanos puestos misioneros" ${ }^{31}$.

Finalmente, el 1 de septiembre de 1718 la comitiva llegó a la misión de Loreto en Moxos. Mayr menciona el recibimiento por parte del Superior Antonio Morillo a su llegada a la capital misional, un día antes de ser designado a Baures, zona en la que 16 años antes el P. Cipriano Barace recibió la palma del martirio.

“Apenas desembarcados a orillas del Marmoré, nos recibieron en compañía de muchos indios que tocaban trompetas, clarinetes, flautas y otros instrumentos, haciendo hermosa música y bailando todos al son de ella. Nos condujeron por arcos de triunfo, hechos de ramas entrelazadas, a través del apretado gentío indígena a la iglesia, dedicada a Nra. Señora de Loreto. Cantamos el Tedeum, dando gracias a Dios y a su Santísima Madre por haber superado tan largo y penoso viaje y ofreciendo de nuevo nuestras vidas al servicio espiritual de los paganos" 32 .

El testimonio es único en cuanto a que da noticia de los componentes coreográficos de una entrada civil (teatro, música, baile) y del carácter escénico reforzado por la arquitectura efímera de una fiesta -en este caso el recibimiento de un nuevo Padre- en territorio misional. El jesuita también informa que los intérpretes indios tocaban música de compositores alemanes, acompañada de bailes españoles, ya que uno de ellos había sido alumno del P. Antonio Sepp, reconocido músico de academias europeas, de origen tirolés ${ }^{33}$.

En la carta del jesuita aparece un despliegue de personajes coetáneos entre los que destacan sus compañeros de viaje; pero además, también nombra a los pilares quienes sentaron las bases de las reducciones -su nuevo lugar de enunciación-, como el ya mencionado Barace. El ferviente deseo de Mayr respecto a su antecesor es el siguiente: “quiera Dios que también yo reciba aquella corona que pocos años ha tocó en suerte a nuestro P. Cipriano Barraza, cuando estos mismos bauros lo mataron a causa del evangelio" ${ }^{34}$. Tanto en su correspondencia personal como en la institucional el Padre alemán presenta a otro de sus modelos de imitación y se declara fiel discípulo de San Francisco Javier, de quien trata de imitar sus pasos. La referencia aparece en su carta, del 31 de diciembre de 1719, dirigida al Provincial Antonio Garriga:

"Estoy persuadido de que hay muchos jóvenes en Alemania que nada desearían más ardientemente que predicar el Evangelio a los paganos, especialmente en estas misiones tan arduas si meditasen las palabras que escribe San Francisco Javier, espejo y maestro de misioneros, en el libro IV de sus Epístolas, capítulo 4: "Muchos estudiantes sacrificarían toda su

\footnotetext{
${ }^{29}$ Mayr, 1969a: 222 y 228.

${ }^{30}$ Sierra, 1944: 119.

${ }^{31}$ Mayr, 1969a: 228.

${ }^{32}$ Ibíd.: 229.

33 Mayr, 2002: 124-125; Meier, 2007: 267

${ }^{34}$ Mayr, 1969a: 230.
} 
solicitud y ciencia por la conversión de los paganos, una vez que hubieran gustado las delicias celestiales que producen tales trabajos»...si su Rev. llegase a conocer jóvenes de buena disposición entre los estudiantes de nuestros colegios, hermanos u otros solicitasen su admisión en la Compañía, le ruego que se digne confirmarlos en su vocación, así como me confirmó y consolidó a mí, enviándome a las Indias "35.

A casi diez años de su arribo, Mayr se muestra agradecido y conforme con sus labores en Moxos. En su carta del 20 de julio de 1727 al Provincial Juan de Espejo, pone ante él su "obediencia, si no es por presencia, al menos por la pluma”. Esto nos remite directamente al "fin de la escritura" del que hablaba el secretario Juan de Polanco en 1547 y que se volvió un motivo literario con las Epístolas del santo patrono de los misioneros, debido a que, explica Mayr, "el poder y el afecto de un sincero y fraternal amor como escribía San Francisco Javier a los suyos, es tan fuerte y penetrante, que incluso muy alejados el uno del otro, el amigo está tan presente al amigo como si se vieran cara a cara" ${ }^{36}$.

Cabe aquí apuntar que la escritura de Francisco Javier en los Llanos de Moxos no es una referencia al bagaje literario de un jesuita en particular, sino a una práctica de lectura colectiva. Al momento del éxodo jesuita, las autoridades militares levantaron inventarios de los bienes y temporalidades de sus misiones, es decir, útiles y efectos pertenecientes al pueblo-familia, no a la iglesia. El escribano civil de uno de esas relaciones registró las posesiones de la misión de Desposorios, la más cercana a Santa Cruz de la Sierra, en donde sobresale la Vida del P. Francisco Javier, escrita en latín por Horacio Turselino y traducida al español en Valladolid donde vio la estampa en 1600. Además, en la capilla de la Procuraduría de Paila, puerto de tipo comercial exclusivo de las reducciones en el río Guapay y único punto de entrada a Moxos y Chiquitos, se halló la efigie del Santo, así como un volumen de las famosos Epístolas de San Javier (Francisci Xaverii epistolarum libri IV), editadas en Roma por el mismo Turselino en $1596,{ }^{37}$ y a las que Mayr hacía mención.

Por tanto, es válido afirmar que estas referencias -la de Barace y las de San Francisco Javier- ilustran claramente la difusión e impacto de la publicación y circulación de las vidas ejemplares de los mártires jesuitas. Mayr declara en 1729 que en su largo camino "ha podido recoger una abundante y justa cosecha javeriana" ${ }^{38}$. Este mismo juego semántico sobre la recolección de frutos, producto de la labranza misional, reaparece en el título del relato póstumo de su estadía en Moxos, lo que convierte a los territorios nativos americanos en un espacio natural de oportunidad para la salvación, en un "jardín de almas" que se debe cultivar ${ }^{39}$. La experiencia personal en el Alto Perú se hizo noticia (probablemente exótica) a un continente de distancia y

\footnotetext{
${ }^{35}$ Mayr, 1969b: 244.

${ }^{36}$ Mayr, 1969c: 366.

37 Tormo Sanz, 1985: 174-178; Romero Romero, 1992: 905, 918.

38 Así lo escribe en su lengua materna: "tausendfache und recht Xaverianische Ernten einsammeln mögen” (2002: 76).

39 En Augsburgo, Bernhard H. Mayr recopiló y mandó publicar en 1747 la obra de su tío, que lleva por título, Dominikus Mayr, Neu-aufgerichteter Americanischer Mayerhof. Das ist: Schwere Arbeiten und reiffe Seelen-Früchten Neuerdings gesammelt; disponible en el acervo digital de la Biblioteca Estatal de Baviera: http://reader.digitale-sammlungen.de/en/fs3/object/display/bsb11092452_00007.html?zoom=0.5.
} 
transmitía tanto el avance moral de los indígenas como la voluntad de sacrificio del viajero, misionero y escritor.

Mayr falleció el 31 de diciembre de 1741 en Baures y aunque su deceso no fue lo violento que él hubiera imaginado, la impresión de sus cartas y el relato de viaje a cinco años de su muerte lo vincula de lleno con la propaganda jesuita mediante la actualización de uno de sus mayores iconos, ya que se le consideraba como el Francisco Javier sudamericano ${ }^{40}$. De hecho, el investigador Dietrich Briesemeister documenta la promoción que hubo en las décadas de 1740-1760 sobre la posible beatificación de Mayr. A ésta hay que añadir otra campaña proselitista que culminó con la declaración de Francisco Javier como el Santo Patrono de Oriente en $1748^{41}$.

La obra póstuma de 1747 incorpora un grabado que sirvió de modelo para los retratos conservados del misionero augsburgués. Los rótulos que acompañan a un par de ellos (Fig. 3) apuntan el olor de santidad con el que Mayr murió. A los dos años de su defunción se abrió su tumba y hallaron al cadáver "integrum, flexible, et recenti sanguine manans”.

En estos retratos ideales (versus verae efigies) se despliega el repertorio iconográfico tradicional (cruz, bautizo, redención, pirámide-perfección, palmera, montañas, fortificación-reducción) para la alabanza de cualquier jesuita que deja su nación para adentrarse a tierra de infieles con riesgo, pero también con ánimo, de perder la vida ${ }^{42}$. Para David Block, figura prominente en la historiografía de Moxos, tanto la posición erguida y la expresión beatífica del misionero, como la actitud sumisa y de agradecimiento del neófito que lo acompaña, estereotipan la representación europea de la experiencia misionera y tipifican la mentalidad que subyace a ella ${ }^{43}$. Galaxis Borja González explica que las representaciones visuales de Mayr, muerto y ausente, "invitaban a los espectadores a imaginar el lugar donde actuaba el compatriota, a identificarse emocionalmente con su tarea evangelizadora y civilizadora, y sentirse de esa forma, parte de ese espacio misionado, distante pero que, gracias a la narración, resultaba ahora inteligible" ${ }^{44}$.

\footnotetext{
${ }^{40}$ Ya en 1726, en Graz, el jesuita Joseph Stöcklein había comenzado su proyecto editorial, El nuevo mensajero del mundo, "primera revista misionera en idioma alemán, en la que se recogían cartas, noticias e informaciones de diversa índole, enviadas desde las misiones en América, Asia y África por jesuitas adscritos a las casas alemanas de la Orden” (Borja González, 2012: 170). El quinto y último volumen de esta publicación periódica apareció en 1761. Albrecht Classen afirma que la traducción al español preparada por Mauro Matthei en 1969, Cartas e informes de misioneros jesuitas extranjeros en Hispanoamérica (3 vols.), utilizada en las citas del presente trabajo, pertenecen a la colección de cartas editadas por Joseph Stöcklein (Classen, 2014: 80).

${ }^{41}$ Briesemeister, 2007: 359; González Magaña, 2007: 120.

${ }^{42} \mathrm{Al}$ respecto, véase el capítulo de Gabriela Torres Olleta que describe la "Tipología iconográfica de San Francisco Javier”, así como las ilustraciones que pudieron haber servido de inspiración para los retratos de Dominik Mayr (2009: 415-450, 558 y 622).

${ }^{43}$ Block, 1997: 178-179.

${ }^{44}$ Borja González, 2012: 180.
} 

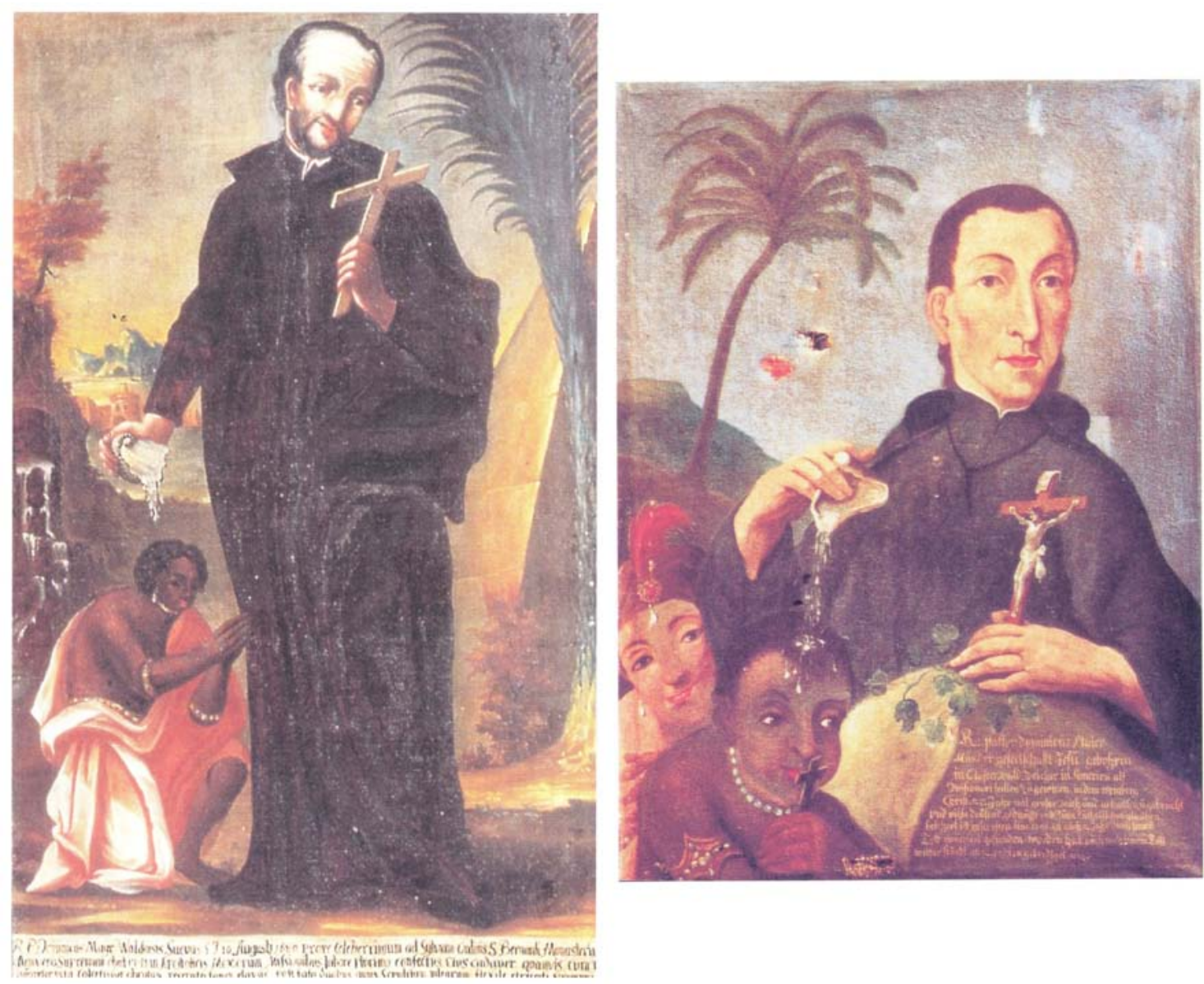

Fig. 3. P. Dominicus Mayr (Terra Amazonum) $)^{45}$

Gracias a los relatos y retratos los misioneros germanos regresaron post mortem a sus comunidades de origen donde los lectores accedían a las noticias de sus compatriotas en ultramar. Los novicios de la Compañía disfrutaban de los martirologios y se aventuraban con ansias hacia las Indias. Dominik Mayr es un excelente ejemplo del empeño puesto por las provincias extranjeras que aportaron misioneros a la América española. A través de la red de comunicación jesuita circularon los viajeros que iban a destino misional y después de su ministerio la misma red los llevaba de vuelta, no como individuos sino como narrativas de vidas ejemplares que promovían la retroalimentación del empeño en Ultramar. Fue en la fuerza de voluntad y en el convencimiento de estos jesuitas que llegaban a los Llanos donde yacen los cimientos del máximo esplendor de la Misión de Moxos durante el primer tercio del siglo XVIII.

\section{Conclusiones}

La idea de circulación es clave para la geografía humana; su dinámica genera cambio en las distintas regiones por las que cruzan objetos y personas. Dentro de la Compañía de Jesús la pre-elaboración de los mensajes, su periodicidad y la participación de los medios tecnológicos para su circulación y recepción, subrayan el carácter reproductivo del discurso y conforman en sí una teología de la comunicación prefigurada por San Ignacio y sus secretarios. Para ellos el arte de la escritura no solo

\footnotetext{
${ }^{45}$ Mayr, 2002: 233 у 235.
} 
queda sancionado por preceptivas que normalizan el contenido, sino por un proceso de mediación tecnológica que regula la frecuencia, la trayectoria y el tipo de mensajes. La proliferación del registro escrito para los jesuitas, en el formato de cartas annuas, correspondencia personal, crónicas, reportes, inventarios y mapas, así como las preceptivas que regulaban su producción y distribución, hicieron posible tanto la comunicación a distancia como el manejo de los medios comunicativos como fuente para mantener y establecer comunidades.

La Compañía supo mantener su sistema de comunicación no solo a través de correspondencia personal, sino por una regulación de misivas anuales y cuatrimestrales cuya serie tenía la posibilidad de ser impresa y ampliar así el número de sus lectores. Durante más de treinta años (1583-1614) la publicación de las annuas consolidó el control editorial en Roma, el cual sirvió para estandarizar el género, sancionar el contenido y legitimar la difusión de textos narrativos que podrían no ser clasificados como teológicos o espirituales, pero que sin duda aseguraron el éxito en las prensas seculares así como los fondos necesarios para la manutención del propio sistema.

Las menciones de lugares conocidos y los vínculos con personas coetáneas a Domink Mayr superan por mucho la aparición de personajes y localidades simbólicas; sin embargo, es posible verificar las referencias pertenecientes a un corpus de conocimiento propio de la Compañía del que Moxos se sirve para atraer recursos, pero que también exporta personajes e historias para ampliar un repertorio global. A la geografía física del territorio y a los vínculos personales se les añaden pocas menciones a instancias simbólicas, pero con el suficiente significado para dotar de sentido a los lugares, personas y situaciones aludidas. Dichas referencias aluden al mundo conocido y son clave en la disposición y consumo de los textos. Mayr ha leído esas vidas ejemplares, como la de San Francisco Javier, y afronta su labor en las reducciones de Baures con la misma tenacidad con la que el mártir de Moxos, Barace, inició la conversión de aquellos indígenas. El viaje de vuelta efectuado por Mayr hacia su tierra natal no solo llevó noticias personales, sino el compendio escrito de parajes lejanos en los que fue posible intervenir directamente.

La escritura de Mayr, informativa y contemplativa, fortaleció la unión espiritual con los suyos sin importar la separación física de la tierra. Su celo impaciente abrió cristiandades en una gesta civilizatoria que invirtió todo tipo de recursos en tierras americanas. Arriba mencioné que los objetivos de la escritura ignaciana trazan un eje que conecta el mundo espiritual con el terrenal, pero también con el íntimo, sentimental y emotivo del misionero. En julio de 1727 Mayr escribió a su hermano, regidor de Constanza, para notificarle su buen estado de salud y de espíritu, “enviándoles cada día mi bendición sacerdotal desde América hasta Europa. Espero que en cambio allá se acuerden de mí y de mis intenciones en estas bárbaras soledades, a fin de que no me vea privado del cielo, después de haber enviado a tantos a él” ${ }^{46}$. Mientras que ésta es la verdadera cosecha que el alemán reclama (émula de la de San Francisco Javier), la remuneración afectiva que solicita es que de él se guarde memoria en lugares tan apartados.

${ }^{46}$ Mayr, 1969d: 375. 


\section{Bibliografía}

Bailey, Gauvin (1999), Art on the Jesuit Missions in Asia and Latin America, 15421773, Toronto: Toronto University Press.

Block, David (1997), La cultura reduccional de los llanos de Mojos: tradición autóctona, empresa jesuítica y política civil, 1660-1880, Sucre: Historia Boliviana.

Borja González, Galaxis (2012), "Las narrativas misioneras y la emergencia de una conciencia-mundo en los imperios jesuíticos alemanes en el siglo XVIII”. Procesos. Revista Ecuatoriana de Historia, 36, pp. 169-192.

Briesemeister, Dietrich (2007), “José Domingo Mayr en tierras de las mujeres guerreras”. En Kohut, Karl y María Torales (eds.), Desde los confines de los imperios ibéricos: los jesuitas de habla alemana en las misiones americanas, Madrid: Iberoamericana, pp. 357-376.

Classen, Albrecht (2014), “A Global Epistolary Network: Eighteenth-Century Jesuit Missionaries Write Home with an Emphasis on Philipp Segesser's Correspondence from Sonora/Mexico”. Studia Neophilologica, 86, pp. 79-94.

Clossey, Luke (2008), Salvation and Globalization in the Early Jesuit Missions, New York: Cambridge University Press.

Constituciones de la Compañía de Jesús (1993), Arzubialde, Santiago, et al. (eds.), Bilbao: Sal Terrae.

Cushner, Nicholas (2006), Why Have You Come Here? The Jesuits and the First Evangelization of Native America, Oxford: Oxford University Press.

Dürrhaim, Franz Xaver (1969), “Carta del R.P. Francisco Javier Dirrheim, misionero de la Compañía de Jesús, de la Provincia de Germania Superior, al R.P. Pedro Mantelo, rector; al P. Nicolas Kost, su padre espiritual, y a Marcquardo, su primo, escrita en la Reducción de Sta. Ana, reino del Perú, el 20 de sept. De 1732”. En Matthei, Mauro (ed.), Cartas e informes de misioneros jesuitas extranjeros en Hispanoamérica III, Santiago: Universidad Católica de Chile, pp. 293-297.

Elliott, John H. (2006), Empires of the Atlantic World: Britain and Spain in America, 1492-1830, New Haven: Yale University Press.

Friedrich, Markus (2008a), "Circulating and Compiling the Litterce annuœ: Towards a History of the Jesuit System of Communication”. AHSI, 153, pp. 1-39.

(2008b), "Government and Information-Management in Early Modern Europe. The Case of the Society of Jesus (1540-1773)". Journal of Early Modern History, 12, pp. 539-563.

Galán García, Agustín (1995), El "oficio de Indias" de Sevilla y la organización económica y misional de la Compañía de Jesús, Sevilla: Fundación Fondo de Cultura de Sevilla.

Harris, Steven (1996), "Confession-Building, Long-Distance Networks, and the Organization of Jesuit Science”. Early Science and Medicine, 3, 1, pp. 287-318. 
Ignacio de Loyola, San (1963), “Al P. Pedro Fabro, 10 diciembre 1542”. En Iparraguirre, Ignacio (ed.), Obras completas, Madrid: Editorial Católica, pp. 648-550.

Izquierdo, Sebastián (1944), “Memorial que el P. Sebastián Izquierdo, asistente en Roma por las Provincias de España, envió al Procurador General de Indias, en la Corte de Madrid, el año de 1673, para dar a la estampa”. En Ed. Sierra, Vicente (ed.), Los jesuitas germanos en la conquista espiritual de Hispano-América, Buenos Aires: Taller Gráfico de Padilla y Contreras, pp. 407-412.

López Castillo, Gilberto (2013), “De la "ciudad eterna" a las "misiones más remotas": comunicación epistolar de los generales con los jesuitas de Sinaloa, 1591-1630”. IHS, 1, 2, pp. 121-136.

Massimi, Marina (2008), "Engenho e temperamentos nos catálogos e no pensamento da Companhia de Jesus nos séculos XVII e XVIII”. Rev. Latinoam. Psicopat. Fund., 11, 4, pp. 675-687.

Mayr, Dominicus (1969a), “Carta del P. Domingo Mayr, de la provincia de Alemania del Sur, a su cuñado en dicho País, escrita en la reducción de Concepción de los Baures, en el país de los indios mojos, el 30 de septiembre de 1718”. En Matthei, Mauro (ed.), Cartas e informes de misioneros jesuitas extranjeros en Hispanoamérica II, Santiago: Universidad Católica de Chile, pp. 222-230.

(1969b), "Carta del P. Domingo Mayr, misionero de la provincia de Alemania del Sur, a su Provincial, escrita en la reducción de la Inmaculada Concepción de María de los Baures, país de los Mojos, 31 de diciembre de 1719”. En Matthei, Mauro (ed.), Cartas e informes de misioneros jesuitas extranjeros en Hispanoamérica II, Santiago: Universidad Católica de Chile, pp. 242-247.

(1969c), “Carta del P. Domingo Mayer S.J, traducida del latín al alemán, a su Provincial, escrita en la reducción de la Inmaculada Concepción de los baures o mojos, el 20 de julio de 1727”. En Matthei, Mauro (ed.), Cartas e informes de misioneros jesuitas extranjeros en Hispanoamérica III, Santiago: Universidad Católica de Chile, pp. 365-374.

(1969d), “Carta del P. Domingo Mayer S. J. a su hermano, Francisco Juan Ignacio Mayer, regidor de Constanza, escrita en la reducción de Inmaculada Concepción de Baures, el 30 de julio de 1727”. En Matthei, Mauro (ed.), Cartas e informes de misioneros jesuitas extranjeros en Hispanoamérica III, Santiago: Universidad Católica de Chile, pp. 374-375.

----------- (2002), Terra Amazonum oder Landschafft der streitbahren Weiber, Stadelmann, Karl-Heinz (ed.), Konstanz: Isele.

Meier, Johannes (2007), “La importancia de la música en las misiones de los jesuitas de habla alemana en Iberoamérica (siglos XVII y XVIII)”. En Kohut, Karl y María Torales (eds.), Desde los confines de los imperios ibéricos: los jesuitas de habla alemana en las misiones americanas, Madrid: Iberoamericana, pp. 265-288.

Nyel, Juan Antonio (1708), "Lettre du Père Nyel, missionnaire de la Compagnie de Jésus, au R. Père Dez de la même Compagnie, recteur du Collège de Strasbourg. 
20 May 1705”. À Le Gobien, Charles (éd.), Lettres édifiantes et curieuses écrites des missions étrangères VIII, Paris: Nicolas le Clerc, pp. 1-27.

Orellana, Antonio (1704), Relacion summaria de la vida, y dichosa muerte del V.P. Cypriano Baraze de la Compañia de Iesus, muerto á manos de barbaros en la Mission de los Moxos de la Provincia del Perú, Lima: Imp. Real de Joseph de Contreras.

Parker, Geoffrey (1998), The Grand Strategy of Philip II, New Haven: Yale University Press.

Pastells, Pablo (1918), Historia de la Compañía de Jesús en la Provincia del Paraguay. T. III, Madrid: Librería General de Victoriano Suárez.

- (1946), Historia de la Compañía de Jesús en la Provincia del Paraguay. T. VI, 1715-1731, Madrid: CSIC.

Polanco, Juan de (1960), "Del offiçio del secretario que estará en Roma”. En Scaduto, Mario, "Uno scritto ignaziano inedito: il Del offiçio del secretario del 1547". AHSI 29, pp. 313-328.

Romero Romero, Catalina (1992), “Tres bibliotecas jesuitas en pueblos de misión: Buenavista, Paila y Santa Rosa, en la región de Moxos”. Revista de Indias, 195196, pp. 889-921.

Ruiz, Elisa (1999), “Arqueología del libro impreso: la Passio sanctorum martyrum Facundi et Primitivi”. En Cátedra, Pedro (ed.), El escrito en el Siglo de Oro: prácticas y representaciones, Salamanca: Universidad de Salamanca, pp. 253288.

Sierra, Vicente (1944), Los jesuitas germanos en la conquista espiritual de HispanoAmérica, Buenos Aires: Taller Gráfico de Padilla y Contreras.

Stadelmann, Karl-Heinz (2002), “Anhang”. In Mayr, Dominicus, Terra Amazonum oder Landschafft der streitbahren Weiber, Konstanz: Isele, pp. 267-302.

Tormo Sanz, Leandro (1985), “Una biblioteca perdida en los llanos del Mamoré”. En Fuentes para la historia de la Iglesia en Bolivia (una guía preliminar), La Paz: Cehila y Ceprolai, pp. 174-178.

Torres Olleta, Gabriela (2009), Redes iconográficas: San Francisco Javier en la cultura visual del Barroco, Madrid: Iberoamericana.

Villalba, Jorge y José Ma. Vargas (2001), "Patronato español de Indias: 2. Práctica: reclutamiento y envío de misioneros”. En O’Neill, Charles y Joaquín Domínguez (eds.), Diccionario histórico de la Compañía de Jesús III, Roma: IHSI, pp. 3061-3062.

Zupanov, Ines (2001), Disputed Mission: Jesuit Experiments and Brahmanical Knowledge in Seventeenth-century India, Oxford: Oxford University Press. 